Running head: THE OPPORTUNITIES AND CHALLENGES OF DIVERSITY

\title{
The Opportunities and Challenges of Diversity: Explaining Its Impact on Individuals and Groups
}

\author{
Miguel R. Ramos \\ University of Oxford and Instituto Universitário de Lisboa (ISCTE-IUL) \\ Miles Hewstone \\ University of Oxford \\ Manuela Barreto \\ University of Exeter and Instituto Universitário de Lisboa (ISCTE-IUL)
}

Nyla R. Branscombe
University of Kansas

Author's Note

This research was supported by a Marie Curie Intra-European Fellowship (627982) awarded to the first author, grants from The Leverhulme and the Economic \& Social Research Council (ORA programme) to the second author, and a fellowship from the Canadian Institute for Advanced Research Social Interactions, Identity and Well-Being program to the fourth author. Correspondence concerning this article should be addressed to Miguel R. Ramos, Department of Experimental Psychology, University of 
Oxford, Tinbergen Building, South Parks Road, OX1 3PS, Oxford, UK. Email: miguel.ramos@psy.ox.ac.uk. 


\begin{abstract}
Demographic trends reveal that modern societies have become increasingly diverse. Within the social sciences, these changes have been reflected in concerns about the implications of social diversity. Whilst early research noted that diversity may have negative consequences for societies and individuals, more recent scholarship has indicated that diversity is not always translated into negative outcomes. These inconsistent findings initiated a scholarly debate concerning the impact of many different forms of diversity for a host of social outcomes. It is now clear that the boundary conditions of these effects are yet to be fully understood. This Special Issue offers a collection of research advances identifying mediating and moderating variables addressing when and why diversity impacts intergroup relational outcomes. By focusing on different levels of diversity (i.e., in the society and in groups), this research also sheds light on the effectiveness of ideologies and policies for managing diversity.
\end{abstract}

Word count: 146 


\section{The Opportunities and Challenges of Diversity: Explaining Its Impact on Individuals and Groups}

With changes in the global economy and increased availability of communication and transportation networks, the number of migrants around the world has dramatically increased over the last decades (United Nations, 2015). Such changes are already having a massive impact across all spheres of life, including the workplace, neighbourhood environments, and nations. It is thus not surprising to see, within the social sciences (but also outside academic enquiry, in politics, economics, and public debate), concern about the impact of diversity on societies, the consequences of multicultural ideologies and policies, as well as the adaptation of immigrant populations.

Initial interest in the effects of diversity emerged from economics, with research investigating the relationship between income, ethnic, and racial diversity and social cohesion (e.g., Alesina \& La Ferrara, 2000; Costa \& Khan, 2003). However, it was Putnam's (2000) work - carried out in the US - that sparked a heated debate across the social sciences by claiming that ethnically heterogeneous communities are harmful, at least in the short-term, by undermining interpersonal trust and social cohesion. Although this conclusion was later qualified (Putnam, 2007), it initiated a scholarly debate concerning many forms of diversity — not just ethnicity but also gender, age, occupational, and disability — and their consequences for a host of social outcomes. Subsequent research (including an exhaustive meta-analysis by van der Meer \& Tolsma, 2014) intensified this debate by yielding mixed and inconclusive results (Gesthuizen, Van der Meer, \& Scheepers, 2008; Uslaner, 2012; for a review see Portes \& Vickstrom, 2011), especially for data assessing these relationships in European countries (Hooghe, Reeskens, Stolle, \& Trappers, 2009). 
The discussion about the effects of diversity is truly diverse in itself, as it has been a multidisciplinary concern involving a variety of perspectives within the social sciences. Given that diversity research focuses on the relationship between the social context (e.g., diversity in a neighbourhood) and individual-level variables (e.g., trust in members of another social group), we believe that this is particularly fertile ground for social psychologists to apply their methods and theory in explaining some of the current inconsistencies.

The aim of this Special Issue of the European Journal of Social Psychology is to capitalise on the momentum that diversity research has gained and provide a social psychological perspective on this pressing social matter. Specifically, this Special Issue offers a collection of contributions that advance our knowledge of when and why diversity has harmful or positive consequences for individuals and their societies, and illuminates how potential ideologies and policies for managing diversity can be more or less effective. Interest in this research is timely, as demographic trends point to the continued increase of diversity in its many forms. There is, therefore, an urgent need to plan for these changes and it is likely that the quality of this planning will strongly influence the quality of people's lives, and the sustainability of our societies and their economies.

\section{Diversity Research}

In his book Bowling Alone (Putnam, 2000), Robert Putnam presented the largest study of civic engagement in the United States, demonstrating the importance and decline of social capital in the US. Social capital consists of characteristics of social networks such as trust, collaboration, mutual obligations, and acceptance of social norms. Putnam found that, among the communities examined, ethnic diversity was associated with less trust in neighbours, lower political efficacy, lower levels of voter 
registration, less volunteering, less involvement in community projects, and lower contributions to charity (Putnam, 2007). These results were striking, and they strengthened concern, across the social sciences, about the effects of diversity. In economics and sociology, for example, scholars have noted that ethnic and racial diversity is associated with lower school funding (Miguel \& Gugerty, 2005), economic performance (Alesina \& La Ferrara, 2005), social trust, civic engagement, and political participation (Kesler \& Bloemraad, 2010). In a review of 15 studies, it was found that diversity in societies is consistently associated with lower levels of social capital (Costa \& Kahn, 2003).

Although the abovementioned work portrays a gloomy picture of the consequences of ethnic diversity, recent research has questioned the inevitability of these conclusions. For example, in Canada it was found that diversity at the municipal level is positively associated with general trust in others (Kazemipur, 2006). In the UK, scholars reported a negative association between diversity and social capital but noted that this effect depends on variables such as neighbourhood poverty or the respondents' racial and ethnic background (Fieldhouse \& Cutts, 2010). Other authors (Kesler \& Bloemraad, 2010) found that countries that promote equality and the integration of immigrants tend to experience declines in social capital as a function of diversity that are less pronounced than those reported by Putnam (2007). Van der Meer and Tolsma's (2014) meta-analysis of 90 recent papers contributed greatly to this discussion. Not surprisingly, the authors found mixed support for Putnam's hypothesis, but more importantly their findings led them to conclude that "a lack of theoretical substantiation on the mechanisms behind that supposed relationship has only increased the cacophony of seemingly contrary empirical findings" (van der Meer \& Tolsma, 2014, p. 471). To contribute to the identification of these potential mechanisms and the boundary 
conditions of diversity effects, we next describe a series of questions raised by previous work that we believe to be of particular relevance to social psychology.

\section{The Scientific Challenges of Diversity Research}

An analysis of the potential variables explaining the effects of diversity must begin with a discussion of how diversity has been defined and measured in the literature. In what follows, we consider the importance of perceived diversity in particular, and its interaction with individual characteristics, in order to explain when diversity may be harmful or beneficial for intergroup outcomes. We then go on to review and discuss potential mechanisms explaining why diversity might have an impact on these outcomes.

Objective diversity, perceived diversity, and potential moderators. There is no consensual definition of diversity. In the public sphere, diversity is strongly associated with racial heterogeneity (Bell \& Hartman, 2007) and with cultural differences arising from migration (Lentin \& Titley, 2008). In the social sciences though, diversity is often defined as social diversification in terms of a larger variety of social categories. It consists of the social heterogeneity found along numerous dimensions (e.g., ethnicity, religion, culture, age) within a specific area. Diversity tends to refer to group-based attributes that are inborn or largely immutable such as ethnicity or gender, but can also encompass fluid and changeable attributes such as education, work experience, or religious beliefs (Vertovec, 2012). In addition, it can refer to readily visible (or surface) characteristics (such as race, ethnicity, gender), or it can refer to characteristics that are not as easy to identify (deep-level diversity, such as differences in attitudes, values, beliefs; Jehn, Chadwick, \& Thatcher, 1997).

The broad ways in which diversity is defined translate into multiple methods of assessing this variable. Across the disciplines of economics, sociology, and political 
science, research methods have privileged measures assessing "objective" diversity, or demographic diversity. Among these objective measures the most commonly used is the Herfindahl-Hirschman index (Hirschman, 1964) also known as the fractionalization index (Alesina, Devleeschauwer, Easterly, Kurlat, \& Wacziarg, 2003), which indicates the probability that two individuals chosen at random would belong to a different demographic group. Other relevant objective measures are the polarisation index (Montalvo \& Reynal-Querol, 2005) and other indices focusing on the level of dissimilarity and segregation in a given space (Massey \& Denton, 1988). A popular alternative to these indices is to assess relative outgroup size, such as the percentage of minority group members in a country, society, or neighbourhood (e.g., Savelkoul, Hewstone, Scheepers, \& Stolle, 2015). Overall, these measures tap into different aspects of demographic heterogeneity and are not directly comparable (for a more detailed discussion of these indices see Esteban, Mayoral, \& Ray, 2012; Montalvo \& ReynalQuerol, 2005).

Importantly, these measures entail some conceptual caveats. First, categorisation into social groups, even demographic social categories, is often not straightforward or consensually agreed upon. The fact that categorisations are open to negotiation questions the idea that diversity can ever be considered "objective." Also, the same individual can be categorised according to either their race, ethnicity, immigrant status, citizenship, ancestry, or whether s/he is from a visible minority group. It is important to note that these divergent categorisations result in inconsistent measurement across studies, and this in itself may explain some of the contradictory findings found in the literature. Second, measuring diversity uniquely in terms of ethnicity provides a misleading unidimensional perspective on contemporary diversity. Ethnicity overlaps with immigration status, gender, education, and labour experiences, but rarely is there 
an analysis of the interplay between these factors (Vertovec, 2007). Finally, we cannot assume that the diversity observed along these demographic lines corresponds to how it is estimated and perceived by individuals, and might impact their behaviour. Previous work has yielded weak to moderate correlations between "objective" and "perceived" diversity (e.g., Semyonov, Raijman, Tov, \& Schmidt, 2004; Hooghe \& De Vroome, 2013). Objective diversity is typically assessed using areas that are physically defined by governments (e.g., countries, cities, postal codes), and these do not necessarily reflect the immediate environment with which individuals may have contact (Hipp \& Boesen, 2013). Thus, a better understanding of the relationship between the social environment and the individual should serve to enhance our knowledge about the effects of diversity.

Addressing these limitations, and drawing on the idea that individual perceptions mediate the relationship between the environment and behaviour, scholars have pointed to the significance of subjective diversity. Indeed, research has found that the effects of objective diversity on attitudes and behaviour only emerge when diversity is subjectively perceived (Alba, Rumbaut, \& Marotz, 2005; Hooghe \& De Vroome, 2013; Koopmans \& Schaeffer, 2015). In a similar vein, perceived diversity was found to have an independent effect on social cohesion indicators, over and above that of objective diversity (Koopmans \& Schaeffer, 2015). Others have suggested that perceived outgroup size, but not its actual size, is associated with anti-immigrant attitudes (Hooghe \& De Vroome, 2013; Semyonov et al., 2004). Thus, one apparent limitation of many empirical investigations is that they do not measure and test the effects of perceived diversity (for exceptions see Scheepers, Gijsberts, \& Coenders, 2002; Schlueter \& Scheepers, 2010). 
Advances can be made by attempting to understand what contextual, structural, or individual factors might shape these perceptions, or the discrepancy between "objective" and perceived diversity. In social psychology there is a long tradition of considering individual characteristics as moderators of the relationship between the context and intergroup processes (for a recent review see Hodson \& Dhont, 2015). This is consistent with Stolle, Soroka, and Johnston's (2008) argument that there is individual variation in the sensitivity to detect "objective" diversity. Thus, one potential avenue for research aiming to understand the effects of diversity is to examine in detail how individual characteristics might interact with the social environment in shaping one's perceptions of diversity. This is an important issue given that it can potentially dictate individual responses to the environment and thus the effects of diversity on intergroup variables. Researchers have recently begun to examine the moderating role of individual levels of authoritarianism on these processes (Kauff, Asbrock, Thorner, \& Wagner, 2013; van Assche, Roets, Dhont, \& van Hiel, 2014). However, authoritarianism is only one of several potential moderators. Research on intergroup relations has also considered the relevance of personality factors (e.g., Big Five; Costa \& McCrae, 1985), values (e.g., valuing harmony and equality; Heaven, Organ, Supavadeeprasit, \& Leeson, 2006), social dominance orientation (Sidanius \& Pratto, 1999), conservatism (Wilson, 1973), system justification (Jost \& Banaji, 1994), and religious fundamentalism (Batson \& Stocks, 2004). Clearly, however, many other factors remain to be examined. There is thus much scope for social psychology to make a major contribution in explaining when diversity impacts intergroup relations. Although this research trend has just begun, it has the potential to provide a vital contribution to the multidisciplinary debate in diversity research. 
The mechanisms underlying the effects of diversity. Research focusing on the effects of diversity has tended to test a direct relationship between diversity and outcomes, with little empirical effort to explain the mechanisms underpinning such effects. This might possibly be due to researchers' assumption that negative effects of diversity stem from feelings of intergroup threat, although other possible mechanisms, including those that might explain positive effects of diversity, have been less examined. This has attracted criticism, arguing that work has been conducted in an atheoretical manner (e.g., Hewstone, 2015; van der Meer \& Tolsma, 2014). To the best of our knowledge, the only exceptions to this lack of theoretical substantiation have emerged from social psychology. For example, Schmid, Al Ramiah, and Hewstone (2014) showed that the effects of ethnic diversity on outgroup, ingroup, and neighbourhood trust are mediated by intergroup contact and perceived intergroup threat. It was found that positive contact and lower perceived threat associated with diversity suppressed most negative direct effects on trust. Relatedly, Green, Sarrasin, Baur, and Fasel (2015) found that intergroup contact and perceived threat mediated the effect of ethnic diversity on radical right-wing voting.

Other promising mechanisms that might explain the ways in which diversity affects outcomes are through individual characteristics that can emerge (or become more salient) by immersion in a diverse environment. For example, Schmid, Hewstone, and Al Ramiah (2013) demonstrated that ethnic diversity is associated with lower ingroup bias and less social distance, and that this effect is explained by the individuals' increased social identity complexity in ethnically diverse contexts. It has also been found that diversity experiences (e.g., being exposed to diversity courses, community events) are associated with more inclusive intergroup attitudes (for a review see Aberson, 2010). Moreover, being exposed to diversity improves perspective-taking 
regarding outgroup targets (Leung \& Chiu, 2010; Todd \& Galinsky, 2012), and the intergroup contact following from such immersion in a diverse context is likely to increase intergroup empathy (Swart, Hewstone, Christ, \& Voci, 2011).

The affective ties and social identities developed within diverse contexts should also contribute to explaining the effects of diversity on intergroup relations. Affective ties and attachment tend to be seen as preconditions to the formation of social capital (Laurence \& Bentley, 2016) and social cohesion (Greif, 2009). Indeed, research has shown that neighbourhood attachment tends to be lower in more diverse neighbourhoods (Górny \& Toruńczyk-Ruiz, 2014; Greif, 2009; Laurence \& Bentley, 2016), and this might help to explain why diversity erodes social capital in these situations. However, it is important to note that the existing evidence does not rule out alternative explanations, such as the possibility that diverse neighbourhoods might also be poorer neighbourhoods that benefit less from regeneration programmes.

Whilst diversity creates opportunities for intergroup contact, it can also contribute to the increased salience of social categorisation. This categorisation is important for intergroup relations given that individuals tend to experience more positive affect (Otten \& Moskowitz, 2000) and tend to be more helpful towards those they categorise as ingroup versus outgroup members (Gaertner, Dovidio, Anastasio, Bachman, \& Rust, 1993). Sharing social identity is also crucial for the development of trust. Work in experimental economics, for example, has demonstrated that participants who play the "trust game" display significantly more trust for others when they belong to the same ethnic group (Glaeser, Laibson, Scheinkman, \& Soutter, 2000). Likewise, sharing social identity increases cooperation in public goods games (Eckel \& Grossman, 2005) and coordination (Charness, Rigotti, \& Rustichini, 2007). 
It is clear from these findings that how individuals define themselves and who is included in their groups has important implications for determining whom they trust, whom they are willing to help and cooperate with, and with whom they would like to have contact. On the other hand, categorisation into different groups is a precondition for ingroup favouritism to occur (Tajfel \& Turner, 1979). This could potentially lead to status differentiation between groups and pave the way for prejudice and discrimination. It is thus also meaningful to examine how the harmful effects of discrimination and beneficial effects of sharing social identity might in tandem account for the overall effect of diversity on intergroup relations. Evidence of this potential relationship can be found in research showing that stigmatisation of minority groups can undermine shared identity at the neighbourhood level, which in turn can lead to individual disengagement from the community (Stevenson, McNamara, \& Muldoon, 2014).

The research reviewed above provides initial directions, but a lot more needs to be done in order to fully understand the impact of diversity on intergroup relations. Previous research has typically examined a single mechanism (for an exception see Schmid et al., 2014), but it is likely that several variables might be working in parallel. What is more, some of these mechanisms (e.g., discrimination, stigmatisation, and perceived threat) may explain some of the negative implications of diversity, but others should account for the beneficial consequences of diversity (e.g., sharing social identity and intergroup contact). For this reason, a full understanding of the effects of diversity requires the development of more complex models mapping possible suppression of beneficial effects and facilitation of harmful effects that may push or pull in different directions. 


\section{Ideologies and Policies for Managing Diversity}

The increasing diversity in societies today raises important challenges ranging from equality concerns to the optimal placement of individuals in society. To successfully manage diversity, it is important to distinguish whether policies are directed towards society as a whole, or towards smaller social structures within the society, such as work organizations.

The ideology of multiculturalism. Ideologies such as assimilation (Davies, Steele, \& Markus, 2008; Verkuyten, 2005) and colour blindness (Rosenthal \& Levy, 2010) have been studied in relation to diversity. Whilst assimilation promotes the unilateral adoption of the majority group's culture for all groups in society; colour blindness is the disregard of any racial and ethnic categorisations (for reviews of these ideologies, see Berry, 2005; Plaut, 2010; Rosenthal \& Levy, 2010). Despite the wellintentioned goals of these ideologies they are often counterproductive. For example, colour blindness can be endorsed as a well-meaning way of decreasing bias: if one does not notice another's race, then one cannot engage in prejudicial behaviour. However, this is not the case in practice given that people do encode quite effortlessly the race of others (Ito \& Urland, 2003), and making an effort to be colourblind while automatically noticing colour undermines efforts to be unbiased (Norton, Sommers, Apfelbaum, Pura, \& Ariely, 2006). Research has supported this view by revealing that exposure to a colourblind ideology often leads to more racial bias (e.g., Richeson \& Nussbaum, 2004), and ignoring racial difference renders communication less efficient, nonverbal behaviours less friendly, and depletes executive or cognitive capacity (Apfelbaum, Sommers, \& Norton, 2008; Norton et al., 2006). Of importance, these ideologies do not support diversity as they do not acknowledge heterogeneity within societies. 
By contrast, multiculturalism corresponds to the notion that social group memberships are important and add value to the wider society, so they must be acknowledged and valued in diverse settings (for reviews, see Plaut, 2010; Stevens, Plaut, \& Sanchez-Burks, 2008). As such, this ideology focuses on the differences between group memberships, whilst considering their positive consequences for both the individual and society. This has been supported by a long tradition in social psychological and cross-cultural research acknowledging the positive effects of cultural and ethnic minority identities (e.g., Berry, 2001; Branscombe, Schmitt, \& Harvey, 1999; Cohen \& Garcia, 2005; Jetten, Haslam, \& Haslam, 2012; Sellers, Rowley, Chavous, Shelton, \& Smith, 1997). Moreover, research reveals that exposure to an ideological approach acknowledging the importance of diversity (e.g., multiculturalism) reduces majority group members' prejudice towards minorities (Richeson \& Nussbaum, 2004).

Despite its various benefits, multiculturalism as a policy has been criticised recently for promoting the self-segregation of minorities, which can hinder the integration of immigrants into the receiving society's social and economic structures (Koopmans, Statham, Giugni, \& Passy, 2008). There is also resistance from majority group members, who tend to consider multiculturalism as threatening (Verkuyten, 2005). This is especially the case for majority group members who identify strongly with their ethnic group (Morrison, Plaut, \& Ybarra, 2010), those who perceive that intergroup relations are characterised by zero-sum conflict (Correll, Park, Judd, Wittenbrink, Sadler, \& Keesee, 2008), and those who tend to score high on right wing authoritarianism (Kauff et al., 2013). Overall, majority group members tend to believe that multiculturalism is relevant to minority groups (or for their benefit) and feel 
excluded from this ideology (Dover, Major, \& Kaiser, 2016; Plaut, Garnett, Buffardi, \& Sanchez-Burks, 2011).

It is thus clear that multiculturalism may have opposing effects on majority and minority group members and that one of the challenges is to convey this ideology in ways that can benefit both groups. Some recent research has begun to address this possibility. For example, Yogeeswaran and Dasgupta (2014) showed that in response to abstract (compared to concrete) forms of multiculturalism, White Americans exhibit less prejudice against minorities and experience lower perceived threat to their national identity. Another way of making multiculturalism more appealing for majority groups is to change their self-conceptions. Morrison and Chung (2011) demonstrated that white American participants reported more support for multiculturalism when led to define themselves as "European American" rather than as "White."

It follows from these findings that multiculturalism can be a promising ideology for promoting positive intergroup relations. However, more research is needed in order to fully understand how to promote its positive effects. Recent work has suggested that, among majority groups, political conservatism (Yogeeswaran \& Dasgupta, 2014) and right-wing authoritarianism (Kauff et al., 2013) moderate the effects of multiculturalism on intergroup attitudes. Here, individual-level characteristics such as personality factors, values, social dominance orientation, or conservatism might be important for understanding the boundary conditions of the effects of multiculturalism (for a detailed discussion of the moderating role of these variables, see Hodson \& Dhont, 2015).

Another promising avenue for future research is to reframe multiculturalism in terms that are more inclusive of majority groups. This could perhaps involve focusing on group differences with equal emphasis on majority and minority groups, emphasising common goals, or making similarities salient. The challenge would be to 
better understand the delicate balance between recognising differences and developing meaningful similarities, between group identities and individuals, and between equality and differential treatment. Whilst initial research on multiculturalism has focused mainly on the integration of minority groups, research should (and some work already does) account for both majority and minority perspectives with the aim of providing optimal outcomes for both groups.

Managing diversity in the workplace. In employment settings, the inclusion of individuals independent of their demographic background is a matter of fairness and social justice (Eagly, 2016; Van Dijk, Van Engen, \& Paauwe, 2012). Yet, discrimination results in the systematic exclusion of various groups (e.g., women, ethnic minorities, older adults) from many opportunities. Scholars (e.g., Fullinwider, 2014) have advocated in favour of affirmative action and anti-discrimination polices with the aim of restoring social justice. These policies are, however, often misunderstood, and they have met with considerable public resistance (Crosby, Sabattini, \& Aizawa, 2013; Kahlenberg, 2013); in fact, they are considered illegal in some countries (Deitch \& Hegewisch, 2013).

The consequences of different policies in the workplace for organisational dynamics have been widely explored by social psychological research (for recent reviews see Apfelbaum, Phillips, \& Richeson, 2014; Eagly, 2016; Ellemers, 2014; Galinsky, Todd, Homan et al., 2015; Paluck, 2006; Paluck \& Green, 2009). Although many positive effects are documented, such as an increased number of minority members applying to vacancies in organizations with explicit commitment to equality and diversity (McNab \& Johnston, 2002), recent research raises concern that the existence of diversity policies might in fact increase blindness to actual instances of 
discrimination (Kirby, Kaiser, \& Major, 2015). More research is needed to understand how this negative effect can be counteracted.

In addition, researchers have examined how members of majority and minority groups perceive specific policies. One of the most popular and direct forms of affirmative action is the quota-based selection scheme, which ensures that a certain number of jobs are awarded to a particular population (Harrison, Kravitz, Mayer, Leslie, \& Lev-Arey, 2006; Kravitz, 2008; Kravitz \& Platania, 1993). As well intentioned as quota-based selection might be, reactions to these policies are not always positive. In fact, they tend to result in lower perceived social equality and poorer evaluations of leaders (Walker, Feild, Giles, Armenakis, \& Bernerth, 2009; Walker, Feild, Giles, Bernerth, \& Short 2011). Quota-based policies are likely to enhance injustice perceptions, especially for those who do not benefit from them, given that they are thought to violate merit-based norms (Harrison et al., 2006; Slaughter, Bulger, \& Bachioci, 2005; Slaughter, Sinar, \& Bachiochi, 2002). In addition, if implemented without adequate justification of their need, quotas can negatively affect team processes, such as reducing cooperation (Dorrough, Ziolkowska, Barreto, \& Glockner, 2016).

Perhaps ironically, these policies also have the reverse and unintended effect of harming those whom they were meant to benefit (for reviews, see Crosby, Iyer, \& Sincharoen, 2006; Leslie, Mayer, \& Kravitz, 2014). For example, research has shown that women became less interested in leadership positions when gender was decisive in the selection process (e.g., Heilman, Lucas, \& Kaplow, 1990) and often experience selfdoubt when they are hired in this way (Brown, Charnsangavej, Keough, Newman, \& Rentfrow, 2000). This is, however, counteracted when it is made clear that the selection procedure also involved a consideration of merit (Brown et al., 2000). 
Given the clear need for policies that assist organizations with equality and diversity management, research needs to continue moving beyond the identification of positive and negative effects of diversity to identify which policies effectively manage diversity and how they must be implemented to serve this purpose.

\section{Overview of the Current Special Issue}

In this Special Issue of the European Journal of Social Psychology, we aimed to bring together cutting-edge research advancing knowledge of when and why diversity has harmful or positive consequences for individuals and their societies, as well as shedding light on the effectiveness of ideologies and policies in managing diversity. From over 40 initial submissions, we selected nine empirical articles. In this collection we aimed to include a wide scope of perspectives in social psychology, examining different forms of diversity (e.g., ethnic, gender, age diversity), and integrating a variety of methods (e.g., correlational and experimental) focusing on both cross-country comparisons and within-country analyses.

In the first article, van Asche, Roets, Dhont, and Van Hiel report a study addressing the role of authoritarianism in shaping people's perceptions of neighbourhood ethnic diversity and its implications for intergroup relations. With a large neighbourhood-level study in the Netherlands, the authors tested whether authoritarianism moderates the relationship between objective and perceived diversity. They further hypothesised that perceived diversity would mediate the effects of objective diversity on outgroup threat, anxiety, and mistrust. Results from this study showed that among individuals high in authoritarianism, greater objective diversity was associated with outgroup negativity, mediated by increased perceived diversity. On the other hand, those who were low in authoritarianism showed a similar effect that was attenuated because objective diversity was negatively associated with outgroup 
negativity. Notable features of this research are that it assessed both objective and subjective diversity and that it assessed both moderators and mediators of the effects of ethnic diversity, shedding light on why conflicting effects have been documented on prior research.

Toruńczyk-Ruiz and Lewicka present an analysis of perceived diversity at the neighbourhood level and its effects on neighbourhood attachment in Poland. Their research is among the first to examine the impact of ethnic diversity together with two additional relevant sources of heterogeneity at the neighbourhood level — age and income diversity. To further understand the effects of diversity on neighbourhood attachment, the authors test with a large survey the moderating role of neighbourhood ties with outgroup members as well as the mediating role of appraisals of the environment. A further interesting aspect of this research is that objective diversity was calculated using the notion of egohoods (Hipp \& Boesen, 2013), which is based on the idea that neighbourhoods are personally defined, instead of physically determined. Results from an analysis controlling for objective diversity showed that perceived ethnic diversity was positively associated with neighbourhood attachment, mediated by appraisals of the environment. However, the pattern for age and income diversity was reversed, such that among individuals with few ties with neighbours of different ages, there was a negative correlation between age diversity and attachment. Likewise, perceived income diversity was negatively related to attachment. This pattern of results is explained in terms of the socio-cultural context, more specifically, the level and meaning of diversity in society. This research provides an interesting contribution to the discussion of the effects of diversity, by suggesting that they may depend upon the type of diversity being considered. It also highlights the significance of achieving neighbourhood ties with outgroup members for shaping a positive experience. 
With today's increasing international migration, the recognition of minority group rights (on the part of both majority and minority groups) is considered to be one of the main challenges in multicultural societies (Human Development Report, 2004). Christ, Kauff, Schmid, and Hewstone address this issue by investigating whether majority group members' intergroup contact is associated with increased support for ingroup rights among minorities, at the level of the social context. In two studies, the authors examine ethnic diversity at the neighbourhood level. Whilst Study 1 provides a cross-country analysis using the European Social Survey including 22 European countries; Study 2 offers a more detailed analysis using a within-country perspective by means of a large survey in Switzerland. Results from both studies revealed that minority group members are more likely to support anti-discrimination laws and immigrant rights when they live in contexts where majority group members have positive intergroup contact experiences (thus majority group members' contact level has a facilitative, rather than 'sedative', effect on minority members' support for collective action). These findings speak to the significance of the social context in shaping minorities' support for group rights across Europe. They further suggest that increasing positive intergroup contact is a fruitful approach for paving the way to social change and improving the status of minority groups. It follows from this research that the increased intergroup contact facilitated in diverse communities is associated with positive outcomes when this contact is also positive.

The contribution of Sparkman, Blanchar, and Eidelman represents a novel perspective introducing the concept of openness motivation (i.e., the desire for multicultural experiences) as a mechanism fuelling the ability of multicultural experiences to reduce intercultural prejudice. The authors present two studies conducted in the U.S. In Study 1, with cross-sectional data, they found that the frequency of self- 
reported multicultural experiences was associated with greater openness, which in turn was associated with prejudice reduction. These findings were extended in Study 2, where the authors manipulated participants' multicultural experiences. Results from this study revealed that, compared to a control condition, individuals who were exposed to cultural elements and members of foreign cultures reported more openness motivation and less prejudice toward various cultural groups (openness was a partial mediator of this effect). Such findings suggest a positive effect of diversity on the individual. They indicate that being exposed to multicultural environments can improve intercultural attitudes by varying the motivation to re-examine pre-existing assumptions, generate alternative hypotheses, and consider novel information.

The fifth contribution to this Special Issue is among the articles that explore the effectiveness of ideologies and policies in managing diversity. Rios and Wynn provide a stimulating perspective on the ideology of multiculturalism. This ideology has been at the centre of multiple recent debates and has been widely regarded as a viable method for tackling some of the challenges posed by the increased diversity in societies. Despite its positive consequences for minority groups (e.g., Plaut, Thomas, \& Goren, 2009), research has shown that multiculturalism is often resisted by majority group members, particularly those who strongly identify with their ethnicity (Verkuyten, 2005). To attenuate majority group members' resistance to this ideology, Rios and Wynn explore the idea that multiculturalism can be presented in ways that are more suitable and appreciated by the majority. Across two experiments in the U.S., the authors found that highly identified White Americans showed less racial prejudice when exposed to a view of multiculturalism as a concrete learning opportunity, as opposed to a concrete set of policies or a concrete ideology. They also showed that this effect was mediated by high identifiers' increased perception that diversity benefits themselves and society as a 
whole. These findings provide an exciting perspective suggesting a significant way in which to motivate prejudice reduction and support for multiculturalism among majority group members.

A growing critique of multiculturalism is that it neglects majorities and favours ethnic and racial minorities (Goodhart, 2013). To address this issue, scholars argued that societies need a shared sense of national unity across cultural differences (e.g., Cantle, 2012). In their paper, Verkuyten, Martinovic, Smeekes, and Kross identified a number of factors leading to people's support (or rejection) of a common national belonging. The authors present three survey studies in which they explore the role of socio-cultural and inequality beliefs as possible predictors of a sense of common belonging in the Netherlands. In all three studies, endorsement of a right-wing orientation and lower education were associated with lower support of common national belonging. Results also showed that deprovincialisation and autochthony were strong mediators of these relationships. These findings were similar for native majority members and immigrants, and provide a significant initial step for the understanding of how sharing a common belonging may better accommodate diversity.

The seventh paper in this collection moves the focus to the effectiveness of policies to accommodate diversity in the workplace. In this paper, Shaughnessy, Braun, Hentschel, and Peus addressed the process through which quota-based selection systems impact people's decisions to pursue employment. The authors conducted an experimental study in Germany presenting an online press release that included (vs. did not include) information that hiring would be based on quotas. Both male and female participants who read that the company intended to increase either the number of women or of different nationalities among upper management rated the selection process as less procedurally fair, the organisation as less attractive, with less prestige, 
and also anticipated lower organisational support. These evaluations, in turn, predicted less interest in applying for the management position. These findings highlight the perils of quota-based selection. The authors alert us to the need for careful planning when implementing a quota, paying particular attention to adequate communication and changes in the organisational culture.

In a similar vein as the previous paper, Nater and Sczesny investigate how diversity management affects individuals' decisions to pursue employment. However, in their article, Nater and Sczesny examine how different leadership job advertisements affect women's and men's inclination to apply. In an experimental study, participants from different European countries read advertisements with a number of gender policies (no statement vs. women explicitly invited to apply vs. preferential treatment of equally qualified women vs. quota of $40 \%$ women). Results indicated that, compared to the control condition and to men, women in the conditions where they were invited to apply or were treated preferentially reported higher self-ascribed fit, which in turn led them to be more inclined to apply. Interestingly, in the condition where quota regulations were active, female participants revealed neither an increased self-ascribed fit nor higher inclinations to apply. The mechanisms explaining the effects of the quota regulation and the no-statement condition were identical. That is, only participants with higher agency levels were more inclined to apply due to an increase in self-ascribed fit. This research suggests that only some policies may be fruitful in promoting women's interest in leadership positions. These results contribute to our understanding of how diversity in the workplace can be more efficiently managed.

Finally, Faniko, Ellemers, and Derks examined the hypothesis that the 'Queen Bee' effect does not necessarily reflect a reluctance of successful women to support other women as previously supposed. Rather, it reflects senior women's identification 
with other women like themselves, and disidentification with women unlike themselves who do not emphasise their careers. Study 1 was conducted in Switzerland among female employees and was based on an experimental design manipulating the target (either junior or manager position). It was found that, compared to junior women, female managers identified more strongly with successful women and supported measures that would benefit these women. However, they were less identified with women who put their family first, they viewed themselves as more masculine than junior women, and they were less likely to endorse measures to support junior women. In Study 2, the authors used the same study design but this time also recruited male participants in order to compare women's Queen Bee responses to men's Alpha Male responses. They found both Queen Bee and Alpha Male effects. Specifically, both female and male managers rated their masculinity as higher than their same-gender junior colleagues. When compared to male managers, female managers were more strongly identified with their successful senior colleagues. Overall, the authors found that women and men identify with different subgroups of same-gender colleagues as a function of their status and life choices. Another implication is that women managers reported self-group distancing and were more reluctant to support gender equality policies only when those policies were to benefit junior women whom they perceived as different from themselves. Yet, it was also apparent that female managers supported other women who they thought were like themselves and worthy of such support. These findings have important implications for our understanding of how (female) managers respond to gender diversity in the workplace.

\section{Concluding remarks}

Diversity research has yielded discrepant findings (van der Meer \& Tolsma, 2014). To address these inconsistencies, work presented in this Special Issue has 
identified several moderators and mediators of the relationship between diversity and intergroup relational outcomes. Collectively, this research contributes by illustrating the important role of individual differences in moderating how individuals perceive diversity and react to that diversity (van Asche et al., 2016). In addition, it demonstrates that perceived diversity, intergroup contact, and openness motivation contribute to understanding how diversity can be beneficial to intergroup relations (Christ et al., 2016; Sparkman et al., 2016; van Asche et al., 2016). One of the novel aspects of the papers presented here is that the results were obtained with a wide range of previously unexplored outcome variables including outgroup negativity, support for minority group rights, and neighbourhood affect. It also presented the first study examining different dimensions of diversity (i.e., ethnic, age, and income diversity) within the same environment (Toruńczyk-Ruiz \& Lewicka, 2016).

The work exploring the effectiveness of ideologies and policies for managing diversity also contributed interesting and novel findings. Specifically, it was found that different levels of right-wing orientation, education, deprovincialisation, and autochthony are important in determining the effects of ideologies on intergroup relations (Verkuyten et al., 2016). In addition, work presented here provides guidance concerning how multiculturalism should be conveyed so that this ideology is less threatening and more appealing to majority groups (Rios \& Wynn, 2016). Regarding the effectiveness of affirmative action policies, it was found that procedural justice and selfascribed fit following from quota-based selection are significant variables in explaining the effects of these policies on applicants' motivations to apply (Nater \& Sczesny, 2016; Shaughnessy et al., 2016). One important conclusion from this work is that quota-based selection might not be the most effective form of affirmative action. Other less direct forms of affirmative action such as inviting minority group members to apply or treating 
them preferentially are related to greater motivation to apply for leadership positions (Nater \& Sczesny, 2016). Alternatively, if quota-based procedures are used, their implementation needs to be carefully considered so as to prevent these negative reactions.

Despite the significant advances made by the articles in this Special Issue, important conceptual questions still remain. First, outcome variables could be more richly conceptualised, and researchers could employ multi-item measures, which are not currently typical in large survey studies. For example, social capital is a rather broad term, referring to the resources that individuals extract from social networks (Bourdieu, 1997), to the density and number of social ties (Coleman, 1990), or to a public good (Putnam, Leonardi, \& Nanetti, 1994). Scholars have argued that it is crucial to distinguish between bonding social capital (i.e., links with fellow ingroup members) and bridging social capital (i.e., links between groups), but this is often ignored (see, e.g., Savelkoul et al., 2015). In contrast, Van der Meer and Tolsma (2014) are more detailed in their conceptualisation and suggest defining social capital as social cohesion, which in turn can be further divided along the dimensions of formality (formal or informal), mode (attitudinal and behavioural), target (ingroup, outgroup, general population), and geographical scope (neighbourhood, city, and country). These inconsistent conceptualisations and measurement issues limit inter-study comparisons and might create some of the discrepancies found in extant work (Portes \& Vickstrom, 2011). Hence, refining these measures could perhaps explain some of these discrepancies, a task for which social psychologists might be able to offer invaluable guidance. It is also important to note that most outcomes previously analysed in diversity research are psychological variables (e.g., trust), and there is therefore a need for social 
psychologists to contribute to the theoretical refinement of these measures as well as to extend their collaboration to teams designing large-scale surveys.

Second, there is little longitudinal research available; previous work has largely been cross-sectional (for an exception see Laurence \& Bentley, 2016). An analysis of how the effects of diversity evolve over time is crucial, since evidence suggests that examining the long-term and sustained relationship between diversity and intergroup relations might reveal different results from those found so far in cross-sectional work. Specifically, research has shown that, when compared to same-race interactions, interracial interactions produce more stress and anxiety (for a meta-analysis of these findings, see Toosi, Babbitt, Ambady, \& Sommers, 2012; Trawalter, Richeson, \& Shelton, 2009). However, with the increasing opportunities for intergroup contact in highly diverse contexts, it is likely that this contact will reduce intergroup prejudice (for a meta-analysis of this effect, see Pettigrew \& Tropp, 2006). With continued interaction, there is thus evidence that the negative effects of diversity could, in some cases, be suppressed by more positive ones (as shown by Schmid et al., 2014). Consistent with this, scholars have recently argued that the heightened anxiety and other negative outcomes of interpersonal relations may be dissipated with time (MacInnis \& PageGould, 2015). Moreover, apart from disentangling short-term from long-term effects, longitudinal studies can also contribute to our knowledge about causality. In fact, in neighbourhood diversity, for example, there should be a high degree of self-selection (i.e., individuals who are open to diversity are more likely to move into more diverse neighbourhoods). A similar effect could be observed at the workplace with organisations being more open to diversity recruiting a more demographically diverse workforce. In general, however, we would expect weaker self-selection effects for the workplace than the neighbourhood, given a limited supply of jobs, the need to fit one's 
skills to the job, and so on. Nonetheless, these are important confounds, and there is an urgent need for longitudinal work to shed light on these questions.

Furthermore, the increasing mobility of people around the world poses a range of challenges that clearly require certain forms of both identity change and development of new identities for individuals and their societies. It also follows that diversity discourse tends to be orientated in a way such that Whites are seen as the hosts, whilst other ethnic groups are outgroups or guests in their societies. Unfortunately, social identity and categorisation matters have been largely neglected thus far. Future research could perhaps examine intergroup relations in diverse societies in light of the Common Ingroup Identity Model (Dovidio, Gaertner, Hodson, Houlette, \& Johnson, 2005), for example, and study under which circumstances different groups within a neighbourhood might be able to share a common and inclusive identity (i.e., superordinate identity), leading to more positive intergroup attitudes.

Finally, one of the goals of this Special Issue was to understand how current policies manage diversity and may counteract the decline of social capital. It is important to use the knowledge developed in the social sciences to develop analyses that will be of practical benefit to leaders and policy makers responsible for managing the broad range of diversity challenges faced by the world today. However, despite the increasing effort of social scientists to contribute to issues of public policy, the lack of consensus in diversity research limits the impact of science on policy, and may even damage the relationship between science and policy (Eagly, 2016). On top of this, the complex structures promoting discrimination and the disadvantage of certain groups in society may resist future policies. For example, Galinsky and colleagues (2015) have argued that transparency is vital to guarantee that individuals with different demographic characteristics be selected for certain jobs (see also Uhlmann \& Cohen, 
2005). Research has also shown that the language used in job advertisements (e.g., the ideal candidate should be "competitive", "dominant") can lower the motivation of women to apply because of lower perceived fit (Gaucher, Friesen, \& Kay, 2011). Furthermore, it has been found

that monitoring and formal mentoring enhances the number of Black and White women being promoted (Kalev, Dobbin, \& Kelly, 2006). However, despite current policies against discrimination and promoting equality, not all companies follow these procedures, and transparency is far from being a standard in some companies, societies, and countries. This calls for a change in society, and investigating diversity matters. 


\section{References}

Aberson, C. L. (2010). Diversity experiences and intergroup attitudes. The Psychology of Social and Cultural Diversity, 171-189.

Alba, R., Rumbaut, R. G., \& Marotz, K. (2005). A distorted nation: Perceptions of racial/ethnic group sizes and attitudes toward immigrants and other minorities. Social Forces, 84, 901-919.

Alesina, A., \& La Ferrara, E. (2000). Participation in heterogeneous communities. Quarterly Journal of Economics, 115, 847-904.

Alesina, A., Devleeschauwer, A., Easterly, W., Kurlat, S., \& Wacziarg, R. (2003). Fractionalization. Journal of Economic Growth, 8, 155-194.

Alesina, A., \& La Ferrara, E. (2005). Preferences for redistribution in the land of opportunities. Journal of Public Economics, 89, 897-931.

Apfelbaum, E. P., Phillips, K. W., \& Richeson, J. A. (2014). Rethinking the baseline in diversity research: Should we be explaining the effects of homogeneity? Perspectives on Psychological Science, 9, 235-244.

Apfelbaum, E. P., Sommers, S. R., \& Norton, M. I. (2008). Seeing race and seeming racist? Evaluating strategic colorblindness in social interaction. Journal of Personality and Social Psychology, 95, 918.

Batson, C. D., \& Stocks, E. (2004). Core Psychological Functions. Handbook of Experimental Existential Psychology, 141.

Bell, J.M., \& Hartmann, D. (2007). Diversity in everyday discourse: The cultural ambiguities and consequences of "happy talk". American Sociological Review, 72, 895-914. 
Berry, J. W. (2001). A psychology of immigration. Journal of Social Issues, 57, 615631.

Berry, J. W. (2005). Acculturation: Living successfully in two cultures. International Journal of Intercultural Relations, 29, 697-712.

Bourdieu, P. (1998). Practical Reason: On the Theory of Action. Stanford University Press.

Branscombe, N. R., Schmitt, M. T., \& Harvey, R. D. (1999). Perceiving pervasive discrimination among African Americans: Implications for group identification and well-being. Journal of Personality and Social Psychology, 77, 135.

Brown, R. P., Charnsangavej, T., Keough, K. A., Newman, M. L., \& Rentfrow, P. J. (2000). Putting the" affirm" into affirmative action: preferential selection and academic performance. Journal of Personality and Social Psychology, 79, 736.

Cantle, T. (2012). Interculturalism: The New Era of Cohesion and Diversity. Palgrave Macmillan.

Charness G, Rigotti L, \& Rustichini A. (2007). Individual behavior and group membership. The American Economic Review, 97, 1340-1352.

Cohen, G. L., \& Garcia, J. (2005). "I am us": negative stereotypes as collective threats. Journal of Personality and Social Psychology, 89, 566.

Coleman, W. D. (1990). State traditions and comprehensive business associations: a comparative structural analysis. Political Studies, 38, 231-252.

Correll, J., Park, B., Judd, C. M., Wittenbrink, B., Sadler, M. S., \& Keesee, T. (2007). Across the thin blue line: police officers and racial bias in the decision to shoot. Journal of Personality and Social Psychology, 92, 1006.

Costa, P. T., \& McCrae, R. R. (1985). Hypochondriasis, neuroticism, and aging: When are somatic complaints unfounded? American Psychologist, 40, 19. 
Costa, D. L. \& Kahn, M. E. (2003). Civic engagement and community heterogeneity: An economist's perspective. Perspectives on Politics, 1, 103-111.

Crosby, F. J., Iyer, A., \& Sincharoen, S. (2006). Understanding affirmative action. Annual Review of Psychology, 57, 585-611.

Crosby, F. J., Sabattini, L., \& Aizawa, M. (2013). Affirmative action and gender equality. The Sage Handbook of Gender and Psychology, 484-499.

Davies, P. G., Steele, C. M., \& Markus, H. R. (2008). A nation challenged: the impact of foreign threat on America's tolerance for diversity. Journal of Personality and Social Psychology, 95, 308.

Deitch, C., \& Hegewisch, A. (2013). VII Sex and Race Discrimination Litigation Settlements as Opportunities for Organizational Change. Journal of Business and Psychology, 28, 425-438.

Dorrough, Ziolkowska, Barreto, \& Glockner, (2016). University of Exeter. Unpublished paper.

Dover, T.L., Major, B., \& Kaiser, C.R. (2014). Diversity initiatives, status, and systemjustifying beliefs: When and how diversity efforts de-legitimize discrimination claims. Group Processes \& Intergroup Relations, 17, 485-493. http://dx.doi.org/10.1177/1368430213502560.

Dovidio, J. F., Gaertner, S. L., Hodson, G., Houlette, M. A., \& Johnson, K. M. (2005). Social inclusion and exclusion: Recategorization and the perception of intergroup boundaries. The Social Psychology of Inclusion and Exclusion, 245-264.

Eagly, A. (2016). When passionate advocates meet research on diversity, does the honest broker stand a chance? Journal of Social Issues, 72, 199-222.

Eckel, C. C., \& Grossman, P. J. (2005). Managing diversity by creating team identity. Journal of Economic Behavior \& Organization, 58, 371-392. 
Ellemers, N. (2014). Women at work how organizational features impact career development. Policy Insights from the Behavioral and Brain Sciences, 1, 46-54.

Esteban, J., Mayoral, L., \& Ray, D. (2012). Ethnicity and conflict: Theory and facts. Science, 336, 858-865.

Fieldhouse, E., \& Cutts D. (2010). Does diversity damage social capital? A comparative study of neighbourhood diversity and social capital in the US and Britain. Canadian Journal of Political Science, 43, 289-318.

Fullinwider, R. (2014). Affirmative action. In E. N. Zalta (Ed.), The Stanford Encyclopedia of Philosophy (Winter 2014 ed.).

Galinsky, A. D., Todd, A. R., Homan, A. C., Phillips, K. W., Apfelbaum, E. P., Sasaki, S. J., Richeson, J. A., Olayon, J. B., \& Maddux, W. W. (2015). Maximizing the gains and minimizing the pains of diversity: A policy perspective. Perspectives on Psychological Science, 10, 742-748. http://dx.doi.org/10.1177/1745691615598513

Gaertner, S. L., Dovidio, J. F., Anastasio, P. A., Bachman, B. A., \& Rust, M. C. (1993). The common ingroup identity model: Recategorization and the reduction of intergroup bias. In W. Stroebe \& M. Hewstone (Eds.), European Review of Social Psychology (Vol. 4. pp. 1-26). New York: Wiley.

Gaucher, D., Friesen, J., \& Kay, A. C. (2011). Evidence that gendered wording in job advertisements exists and sustains gender inequality. Journal of Personality and Social Psychology, 101, 109.

Gesthuizen, M., Van der Meer, T., \& Scheepers, P. (2008). Education and dimensions of social capital: do educational effects differ due to educational expansion and social security expenditure? European Sociological Review, 24, 617-632.

Glaeser, E. L., Laibson, D. I., Scheinkman, J. A., \& Soutter, C. L. (2000). Measuring trust. Quarterly Journal of Economics, 811-846. 
Goodhart, G. (2013). The British dream: Successes and failures of post-war immigration. London: Atlantic Books.

Górny, A., \& Toruńczyk-Ruiz, S. (2014). Neighbourhood attachment in ethnically diverse areas: the role of interethnic ties. Urban Studies, 51, 1000-1018.

Green, E. G., Sarrasin, O., Baur, R., \& Fasel, N. (2015). From stigmatized immigrants to radical right voting: A multilevel study on the role of threat and contact. Political Psychology, 37, 465-480.

Greif, M.J. (2009). Neighborhood attachment in the multiethnic metropolis. City \& Community, 8, 27-45.

Harrison, D. A., Kravitz, D. A., Mayer, D. M., Leslie, L. M., \& Lev-Arey, D. (2006). Understanding attitudes toward affirmative action programs in employment: summary and meta-analysis of 35 years of research. Journal of Applied Psychology, 91, 1013-1036.

Heaven, P. C., Organ, L. A., Supavadeeprasit, S., \& Leeson, P. (2006). War and prejudice: A study of social values, right-wing authoritarianism, and social dominance orientation. Personality and Individual Differences, 40, 599-608.

Heilman, M. E., Lucas, J. A., \& Kaplow, S. R. (1990). Self-derogating consequences of sex-based preferential selection: The moderating role of initial self-confidence. Organizational Behavior and Human Decision Processes, 46, 202-216.

Hewstone, M. (2015). Consequences of diversity for social cohesion and prejudice: The missing dimension of intergroup contact. Journal of Social Issues, 71, 417-438.

Hipp, J. R., \& Boessen, A. (2013). Egohoods as waves washing across the city: A new measure of"neighborhoods". Criminology, 51, 287-327. 
Hirschman, A. O. (1964). The paternity of an index. American Economic Review, 54, $761-762$.

Hodson, G., \& Dhont, K. (2015). The person-based nature of prejudice: Individual difference predictors of intergroup negativity. European Review of Social Psychology, 26, 1-42.

Hooghe, M., Reeskens, T., Stolle, D., \& Trappers, A. (2009). Ethnic diversity and generalized trust in Europe: a cross-national multilevel study. Comparative Political Studies, 42, 198-223.

Hooghe, M., \& de Vroome, T. (2013). The perception of ethnic diversity and antiimmigrant sentiments: a multilevel analysis of local communities in Belgium. Ethnic and Racial Studies, 38, 38-56.

Human Development Report. (2004). Cultural liberty in today's diverse world. New York: United Nations.

Ito, T.A., \& Urland, G.R. (2003). Race and gender on the brain: Electrocortical measures of attention to the race and gender of multiply categorizable individuals. Journal of Personality and Social Psychology, 85, 616-626.

Jehn, K. A., Chadwick, C., \& Thatcher, S. M. (1997). To agree or not to agree: The effects of value congruence, individual demographic dissimilarity, and conflict on workgroup outcomes. International Journal of Conflict Management, 8, 287-305. Jetten, J., Haslam, C., \& Haslam, S. A. (Eds.). (2012). The social cure: Identity, health and well-being. New York: Psychology Press.

Jost, J. T., \& Banaji, M. R. (1994). The role of stereotyping in system-justification and the production of false consciousness. British Journal of Social Psychology, 33, 127. 
Kahlenberg, R. (2013). The class-based future of affirmative action. American Prospect. Accessed on January $30^{\text {th }}, 2016$. Retrieved from http://prospect.org/article/classbased-future-affirmative-action.

Kalev, A., Dobbin, F., \& Kelly, E. (2006). Best practices or best guesses? Assessing the efficacy of corporate affirmative action and diversity policies. American Sociological Review, 71, 589-617.

Kauff, M., Asbrock, F., Thörner, S., \& Wagner, U. (2013). Side effects of multiculturalism: The interaction effect of a multicultural ideology and authoritarianism on prejudice and diversity beliefs. Personality and Social Psychology Bulletin, 39, 305-320.

Kazemipur, A. (2006). A Canadian exceptionalism? Trust and diversity in Canadian cities. Journal of International Migration and Integration, 7, 219-40.

Kesler, C., \& Bloemraad, I. (2010). Does immigration erode social capital? The conditional effects of immigration-generated diversity on trust, membership, and participation across 19 countries, 1981-2000. Canadian Journal of Political Science, 43, 319-347.

Kirby, T. A., Kaiser, C. R., \& Major, B. (2015). Insidious procedures: Diversity awards legitimize unfair organizational practices. Social Justice Research, 28, 169-186.

Koopmans, R., \& Schaeffer, M. (2015). Statistical and perceived diversity and their impacts on neighborhood social cohesion in Germany, France and the Netherlands. Social Indicators Research DOI: 10.1007/s11205-015-0863-3.

Koopmans, R., Statham, P., Giugni, M., \& Passy, F. (2008). The denationalization of immigration politics. In O. Schmidtke \& S. Ozcurumez (Eds.) Of States, Rights, and Social Closure (pp. 225-256). New York: Palgrave Macmillan. 
Kravitz, D. A. (2008). The diversity-validity dilemma: Beyond selection-the role of affirmative action. Personnel Psychology, 61, 173-193. doi:10.1111/j.17446570.2008.00110.x

Kravitz, D. A., \& Platania, J. (1993). Attitudes and beliefs about affirmative action: Effects of target and of respondent sex and ethnicity. Journal of Applied Psychology, 78, 928-938. doi: 10.1037/0021-9010.78.6.928

Laurence, J., \& Bentley, L. (2016). Does ethnic diversity have a negative effect on attitudes towards the community? A longitudinal analysis of the causal claims within the ethnic diversity and social cohesion debate. European Sociological Review, 32, 54-67. doi: 10.1093/esr/jcv081

Leslie, L. M., Mayer, D. M., \& Kravitz, D. A. (2014). The stigma of affirmative action: A stereotyping-based theory and meta-analytic test for the consequences for performance. Academy of Management Journal, 57, 964-989. doi: 10.5465/amj.2011.0940

Leung, A. K. Y., \& Chiu, C. Y. (2010). Multicultural experience, idea receptiveness, and creativity. Journal of Cross-Cultural Psychology, 4, 723-741.

MacInnis, C. C., \& Page-Gould, E. (2015). How can intergroup interaction be bad if intergroup contact is good? Exploring and reconciling an apparent paradox in the science of intergroup relations. Perspectives on Psychological Science, 10, 307327. http://dx.doi.org/10.1177/1745691614568482

Massey, D. S., \& Denton, N. A. (1988). The dimensions of residential segregation. Social Forces, 67, 281-315.

McNab, S. M., \& Johnston, L. (2002). The impact of equal employment opportunity statements in job advertisements on applicants' perceptions of organisations. 
Australian Journal of Psychology, 54, 105-109. doi:

\section{$10.1080 / 00049530210001706573$}

Miguel, E., \& Gugerty, M. K. (2005). Ethnic diversity, social sanctions and public goods in Kenya. Journal of Public Economics, 89, 2325-2368.

Montalvo, J. G., \& Reynal-Querol, M. (2005). Ethnic diversity and economic development. Journal of Development economics, 76, 293-323.

Morrison, K. R., \& Chung, A. H. (2011). "White” or "European American”? Selfidentifying labels influence majority group members' interethnic attitudes. Journal of Experimental Social Psychology, 47, 165-170.

Morrison, K.R., Plaut, V.C., \& Ybarra, O. (2010). Predicting whether multiculturalism positively or negatively influences White Americans' intergroup attitudes: The role of ethnic identification. Personality and Social Psychology Bulletin, 36, 16481661. http://dx.doi.org/10.1177/0146167210386118.

Norton, M. I., Sommers, S. R., Apfelbaum, E. P., Pura, N., \& Ariely, D. (2006). Color blindness and interracial interaction: Playing the political correctness game. Psychological Science, 17, 949-953.

Otten, S., \& Moskowitz, G. B. (2000). Evidence for implicit evaluative in-group bias: Affect-biased spontaneous trait inference in a minimal group paradigm. Journal of Experimental Social Psychology, 36, 77-89.

Paluck, E. L. (2006). Diversity training and intergroup contact: A call to action research. Journal of Social Issues, 62, 577-595.

Paluck, E. L., \& Green, D. P. (2009). Prejudice reduction: What works? A review and assessment of research and practice. Annual Review of Psychology, 60, 339-367. 
Pettigrew, T. F., \& Tropp, L. R. (2006). A meta-analytic test of intergroup contact theory. Journal of Personality and Social Psychology, 90, 751-783. http://dx.doi.org/10.1037/0022-3514.90.5.751

Plaut, V. C. (2010). Diversity science: Why and how difference makes a difference. Psychological Inquiry, 21, 77-99.

Plaut, V. C., Thomas, K. M., \& Goren, M. J. (2009). Is multiculturalism or color blindness better for minorities? Psychological Science, 20, 444-446.

Plaut, V.C., Garnett, F.G., Buffardi, L.E., \& Sanchez-Burks, J. (2011). "What about me?" Perceptions of exclusion and whites' reactions to multiculturalism. Journal of Personality and Social Psychology, 101, 337. http://dx.doi.org/10.1037/a0022832.

Portes, A., \& Vickstrom, E. (2011). Diversity, social capital, and cohesion. Annual Review of Sociology, 37, 461-479.

Putnam, R. D. (2000). Bowling alone: The collapse and revival of American community. New York: Simon \& Schuster.

Putnam, R. D. (2007). E Pluribus Unum: Diversity and community in the twenty-first century: the 2006 Johan Skytte Prize lecture. Scandinavian Political Studies, 30, 137-174.

Putnam, R. D., Leonardi, R., \& Nanetti, R. Y. (1994). Making Democracy Work: Civic Traditions in Modern Italy. Princeton, NJ: Princeton University Press.

Richeson, J.A., \& Nussbaum, R.J. (2004). The impact of multiculturalism versus colorblindness on racial bias. Journal of Experimental Social Psychology, 40, 417423. http://dx.doi.org/10.1016/j.jesp.2003.09.002.

Rosenthal, L., \& Levy, S. R. (2010). The colorblind, multicultural, and polycultural ideological approaches to improving intergroup attitudes and relations. Social Issues and Policy Review, 4, 215-246. 
Savelkoul, M., Hewstone, M., Scheepers, P., \& Stolle, D. (2015). Does relative outgroup size in neighborhoods drive down associational life of Whites in the US? Testing constrict, conflict and contact theories. Social Science Research, 52, 236252.

Scheepers, P., Gijsberts, M, \& Coenders, M. (2002). Ethnic exclusionism in European countries: public opposition to civil rights for legal migrants as a response to perceived ethnic threat. European Sociological Review, 18, 17-34.

Schlueter, E., \& Scheepers, P. (2010). The relationship between outgroup size and antioutgroup attitudes: a theoretical synthesis and empirical test of group threat and intergroup contact theory. Social Science Research, 39, 285-295.

Schmid, K., Al Ramiah, A., \& Hewstone, M. (2014). Neighborhood ethnic diversity and trust: The role of intergroup contact and perceived threat. Psychological Science, $25,665-674$.

Schmid, K., Hewstone, M., \& Al Ramiah, A. (2013). Neighborhood Diversity and Social Identity Complexity: Implications for Intergroup Relations. Social Psychological and Personality Science, 4, 135-142.

Sellers, R. M., Rowley, S. A., Chavous, T. M., Shelton, J. N., \& Smith, M. A. (1997). Multidimensional Inventory of Black Identity: A preliminary investigation of reliability and constuct validity. Journal of Personality and Social Psychology, 73, 805-815.

Semyonov, M., Raijman, R., Tov, A. Y., \& Schmidt, P. (2004). Population size, perceived threat, and exclusion: a multiple-indicators analysis of attitudes toward foreigners in Germany. Social Sciences Research, 33, 681-701. 
Sidanius, J. \& Pratto, F. (1999). Social dominance: An intergroup theory of social hierarchy and oppression. Cambridge: Cambridge University Press.

Slaughter, J. E., Bulger, C. A., \& Bachiochi, P. D. (2005). Black applicants' reactions to affirmative action plans: Influence of perceived procedural fairness, anticipated stigmatization, and anticipated remediation of previous injustice. Journal of Applied Social Psychology, 35, 2437-2472. doi:10.1111/j.1559-

1816.2005.tb02110.x

Slaughter, J. E., Sinar, E. F., \& Bachiochi, P. D. (2002). Black applicants' reactions to affirmative action plans: effects of plan content and previous experience with discrimination. Journal of Applied Psychology, 87, 333-344. http://dx.doi.org/10.1037/0021-9010.87.2.333

Stevens, F. G., Plaut, V. C., \& Sanchez-Burks, J. (2008). Unlocking the benefits of diversity all-inclusive multiculturalism and positive organizational change. The Journal of Applied Behavioral Science, 44, 116-133.

Stevenson, C., McNamara, N., \& Muldoon, O. (2014). Stigmatised identity and service usage in disadvantaged communities: Residents', community workers' and service providers' perspectives. Journal of Community \& Applied Social Psychology, 24(6), 453-466.

Stolle, D., Soroka, S., \& Johnston, R. (2008). When does diversity erode trust? Neighborhood diversity, interpersonal trust and the mediating effect of social interactions. Political Studies, 56, 57-75.

Swart, H., Hewstone, M., Christ, O., \& Voci, A. (2011). Affective mediators of intergroup contact: a three-wave longitudinal study in South Africa. Journal of Personality and Social Psychology, 101, 1221-1238. 
Tajfel, H., \& Turner, J.C. (1979). An integrative theory of intergroup conflict. In W.G. Austin \& S. Worchel (Eds.) The social psychology of intergroup relations (pp. 3347). Monterey, CA: Brooks/Cole.

Titley, G., \& Lentin, A. (Eds.). (2008). The politics of diversity in Europe. Strasbourg, France: Council of Europe Publishing.

Todd, A. R., \& Galinsky, A. D. (2012). The reciprocal link between multiculturalism and perspective-taking: How ideological and self-regulatory approaches to managing diversity reinforce each other. Journal of Experimental Social Psychology, 48, 1394-1398.

Toosi, N. R., Babbitt, L. G., Ambady, N., \& Sommers, S. R. (2012). Dyadic interracial interactions: A meta-analysis. Psychological Bulletin, 138, 1-27. http://dx.doi.org/10.1037/a0025767

Trawalter, S., Richeson, J. A., \& Shelton, J. N. (2009). Predicting behavior during interracial interactions: A stress and coping approach. Personality and Social Psychology Review, 13, 243-268. http://dx.doi.org/10.1177/1088868309345850

Uhlmann, E. L., \& Cohen, G. L. (2005). Constructed criteria: Redefining merit to justify discrimination. Psychological Science, 16, 474-480.

United Nations (2015). International Migration 2015. Retrieved $29^{\text {th }}$ January, 2016, from http://www.un.org/en/development/desa/population/migration/publications/wallchart/docs/ MigrationWallChart2015.pdf

Uslaner, E. M. (2012). Segregation and mistrust: Diversity, isolation, and social cohesion. New York: Cambridge University Press 
Van Assche, J., Roets, A., Dhont, K., \& Van Hiel, A. (2014). Diversity and out-group attitudes in the Netherlands: The role of authoritarianism and social threat in the neighbourhood. Journal of Ethnic and Migration Studies, 40, 1414-1430.

van der Meer, T., \& Tolsma, J. (2014). Ethnic diversity and its effects on social cohesion. Annual Review of Sociology, 40, 459-478.

van Dijk, H., van Engen, M., \& Paauwe, J. (2012). Reframing the business case for diversity: A values and virtues perspective. Journal of Business Ethics, 111, 73-84. http://dx.doi.org/10.1007/s10551-012-1434-z

Verkuyten, M. (2005). Ethnic group identification and group evaluation among minority and majority groups: Testing the multiculturalism hypothesis. Journal of Personality and Social Psychology, 88, 121-138.

Vertovec, S. (2007). Super-diversity and its implications. Ethnic and Racial Studies, 30, 1024-1054.

Vertovec, S. (2012). "Diversity" and the social imaginary. European Journal of Sociology, 53, 287-312.

Walker, H. J., Feild, H. S., Giles, W. F., Armenakis, A., \& Bernerth, J. B. (2009). Displaying employee testimonials on recruitment web sites: effects of communication media, employee race, and job seeker race on organizational attraction and information credibility. Journal of Applied Psychology, 94, 1354-64. doi:10.1037/a0014964

Walker, H. J., Feild, H. S., Giles, W. F., Bernerth, J. B., \& Short, J. C. (2011). So what do you think of the organization? A contextual priming explanation for recruitment Web site characteristics as antecedents of job seekers' organizational image perceptions. Organizational Behavior and Human Decision Processes, 114, 165178. doi:10.1016/j.obhdp.2010.11.004 
Wilson, G. D. (1973). A dynamic theory of conservatism. In G. D. Wilson (Ed.), The psychology of conservatism (pp. 257-265). London, England: Academic Press.

Yogeeswaran, K., \& Dasgupta, N. (2014). The devil is in the details: Abstract versus concrete construals of multiculturalism differentially impact intergroup relations. Journal of Personality and Social Psychology, 106, 772. http://dx.doi.org/10.1037/a0035830. 